\title{
Microstructural Refinement of an As-Cast Al-12.6 Wt Pct Si Alloy by Repeated Thermomechanical Treatment to Produce a Heavily Deformable Material
}

\begin{abstract}
OSAMU UMEZAWA and KOTOBU NAGAI
A certain degree of cold working is advantageous in developing a fine microstructure with minute silicon crystals for eutectic and/or hypereutectic Al-Si cast alloys. A novel process, repeated thermomechanical treatment (RTMT), was applied to an Al-12.6 wt pet Si cast alloy. The process involves multiple-pass cold working (less than a 20 pct reduction in section area) and heat treatment at 793 $\mathrm{K}$ for $3.6 \mathrm{ks}$. Cold-work annealing was repeated up to about an 80 pct reduction in section from the beginning. The RTMT material showed a refined microstructure with high ductility. Most silicon crystals were fragmented to only a few micrometers and were spheroidized. The RTMT material showed such marked plasticity that it could be wrought up to a 99 pct reduction in section at room temperature. The Cold-worked RTMT materials exhibited an excellent balance between tensile strength and elongation and a higher strain hardening than the cast material.
\end{abstract}

\section{INTRODUCTION}

RECYCLABLE design for sustainable development has been proposed in the design of ecomaterials (environmentally conscious materials), ${ }^{[1,2]}$ and has been discussed in terms of design factors, e.g., recyclability and ecology for raw materials, simplification of recycling and scrapping, and adequately balanced properties. ${ }^{[2,3]} \mathrm{Al}-\mathrm{Si}$ systems, which have plural phases with low mutual solid solubility, are effective as in situ metal-metal composites which possess simplified recycle models and adequately balanced properties such as strength and elongation. ${ }^{[3]}$ Although Al-Si alloys are a major cast material, it is extremely important, from an aluminum recycling standpoint, to improve their ductility.

A look at the stress-strain curves of polycrystalline aluminum (Figure 1(a)) demonstrates that cold-working operation results in an increase in the flow stress and almost no uniform elongation at $293 \mathrm{~K}$. Those are undesirable in balancing higher strength and ductility. To control balanced properties, a fine microstructure with plural phases is one of the candidates for alloy design. ${ }^{[1]}$ Reinforcing aluminum alloys with $\mathrm{SiC}$ particles of approximately equiaxed shapes, on the order of several microns in size, strengthened the alloys at low strains due to the increases in the elastic modulus and strainhardening rate. ${ }^{[4,5]}$ Humphreys ${ }^{[6]}$ reported deformation and recrystallization of two-phase aluminum alloys containing nondeformable large particles a few microns in size. A deformation zone containing a high dislocation density and large lattice misorientations was observed in the vicinity of particles on deformation, indicating that geometrically necessary dislocations ${ }^{[7]}$ are stored in the deformation zone to accommodate deformation gradients. These geometrically necessary dislocations enhance strain hardening, particularly in a low-strain regime.

Heavy cold working cannot, however, be applied to Al$\mathrm{Si}$ cast alloys, because it causes severe cracking in coarse

OSAMU UMEZAWA, Senior Scientist, and KOTOBU NAGAI, Group Leader, are with the Frontier Research Center for Structural Materials, National Research Institute for Metals, Ibaraki 305-0047, Japan.

Manuscript submitted September 24, 1998. primary and/or eutectic silicon crystals. A eutectic Al-Si cast material posesses increased strain hardening at low temperatures accompanied by increased flow stress and decreased strain to failure, although an increase in the strainhardening rate results in greater strain to failure with decreasing temperature for polycrystalline aluminum. For the unmodified Al-Si alloy, the silicon phase must be refined to avoid sample fracture due to cracking.

To improve the mechanical properties of Al-Si cast materials, microstructural modifications have been made by adding elements such as $\mathrm{Sr}$ and $\mathrm{P}$ to the melt, or by hot forging and long-term solution heat treatment. The ductility of treated materials remains insufficient, however, and they cannot be applied to wrought materials. The most promising refining of microstructures is rapid solidification. Spray forming and thixoforming have been used to refine silicon in $\mathrm{Al}-\mathrm{Si}$ alloys. ${ }^{[8]}$ Rapid solidification is not amenable to mass production, however, and we developed a novel thermomechanical treatment for an Al-12.6 wt pct Si cast alloy.

This article details the microstructural refinement of ascast Al-12.5 wt pct Si material by repeated thermomechanical treatment (RTMT) to produce satisfactory ductility and stress-strain curves in Al-Si materials.

\section{EXPERIMENTAL}

\section{A. Material}

A eutectic Al-Si alloy was cast as $5 \mathrm{~kg}$ ingots, herein called the AC material. The chemical composition is given in Table I. The alloy contains both primary and eutectic silicon crystals (Figure 2). The primary silicon forms hexagonal shapes of about $50 \mu \mathrm{m}$ in size. The eutectic silicon is needle- or plate-shaped and is about $5 \times 50 \mu \mathrm{m}$. The solution-treated (ST) sample was heat treated at $793 \mathrm{~K}$ for 3.6 $\mathrm{ks}$, followed by water quenching. The AC samples were machined either as round bars $(30 \mathrm{~mm}$ in diameter $\times 100$ $\mathrm{mm}$ in length) for grooved rolling and swaging or as plates $(10 \times 30 \times 60 \mathrm{~mm})$ for flat rolling.

The tensile properties of polycrystalline aluminum (99.99 


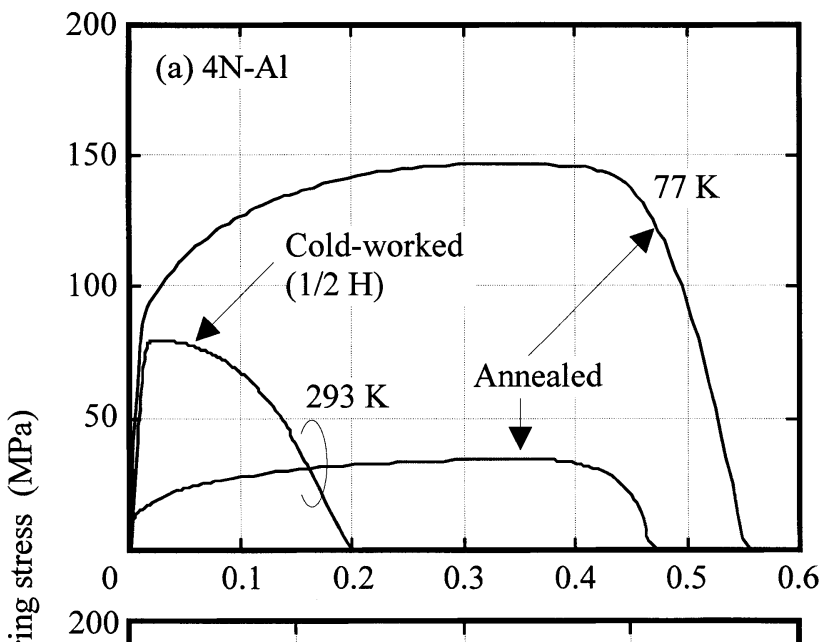

(b) $\mathrm{Al}-12.6 \mathrm{wt} \% \mathrm{Si}$ alloy, as cast

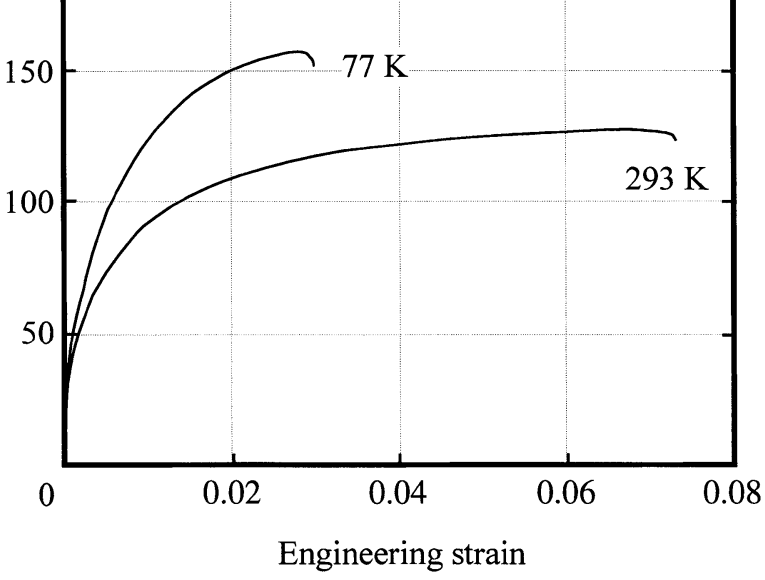

Fig. 1-Stress-strain curves for (a) $4 \mathrm{~N}$ aluminum polycrystalline annealed $(793 \mathrm{~K}, 3.6 \mathrm{ks}, \mathrm{WQ})$ and cold worked (1/2 hard); and (b) Al-12.6 wt pct Si cast material (AC).

Table I. Chemical Compositions of Eutectic Al-Si Alloy

\begin{tabular}{cccccccccc}
\hline Element & $\mathrm{Si}$ & $\mathrm{Cu}$ & $\mathrm{Fe}$ & $\mathrm{Ni}$ & $\mathrm{Ti}$ & $\mathrm{Mg}$ & $\mathrm{Zn}$ & $\mathrm{Mn}$ & $\mathrm{Al}$ \\
\hline $\begin{array}{c}\text { Concentration } \\
\text { (wt pct) }\end{array}$ & 12.60 & 0.01 & 0.14 & 0.04 & 0.05 & 0.00 & 0.00 & 0.00 & bal \\
\hline
\end{tabular}

pct) were also studied as a reference. A commercial aluminum bar in the $1 / 2$ hard (cold-worked) condition was used and was annealed at $793 \mathrm{~K}$ for $3.6 \mathrm{ks}$, followed by water quenching.

\section{B. Cast Material Workability}

To clarify the fracture resistance and cracking of silicon crystals for the AC material, one-pass rolling tests were carried out at different temperatures using the plate sample. The sample temperature on the inlet side was at 77, 293, 393, 493, 543, 593, 643, 693, 743, and $793 \mathrm{~K}$. The section area was reduced by either 20 or 50 pct. The load for the work roll was monitored during rolling, and the peak load was measured to observed deformation resistance in various conditions. The rotation speed of the work roll was 5

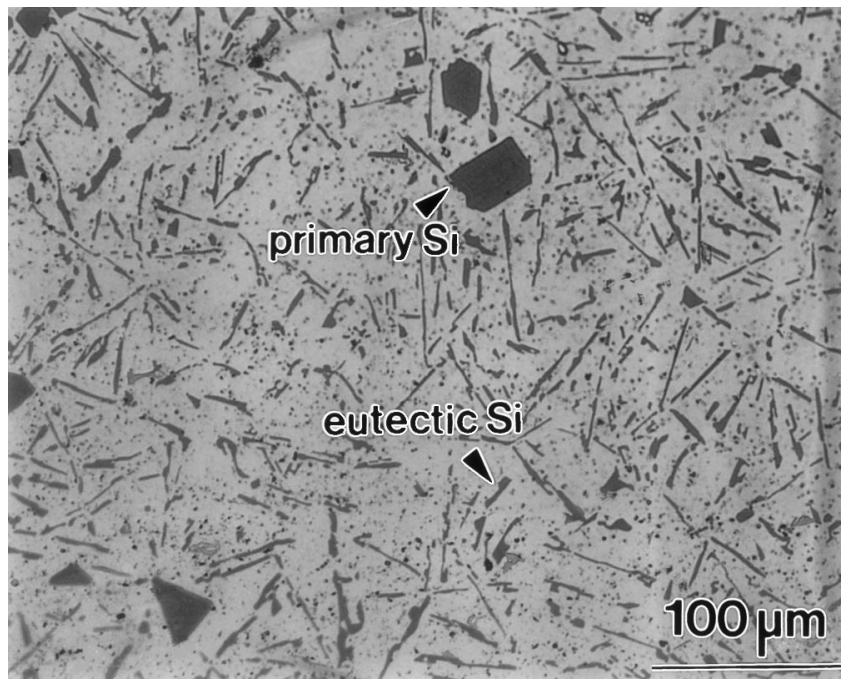

Fig. 2-Microstructure of AC material.

$\mathrm{m} / \mathrm{min}$. At $293 \mathrm{~K}$, the reduction limit within multiple-step working was also studied for swaging and flat rolling.

\section{Repeated Thermomechanical Treatment}

To avoid fracture, cold working was applied to round bar samples in several steps with intermediate annealing, using the RTMT process. ${ }^{[9]}$ We conducted cold working by flat rolling, V-shaped grooved rolling, or swaging in multiple passes or steps at room temperature and formed the samples into either sheet or wire. Annealing was at $793 \mathrm{~K}$ for 3.6 ks followed by water quenching. The cold reduction was less than 20 pct in section area, and cold-work annealing was repeated over six times for a total reduction of about 80 pct in area. In swaging, the die diameters were 27,24 , $21,18,16$, and $14 \mathrm{~mm}$. In both grooved rolling and flat rolling, the reduction in the first cold-working cycle was less than $10 \mathrm{pct}$, then the process was repeated up to eight times.

For the resulting RTMT materials in the final annealed state, multiple-pass working, either by swaging or flat rolling at room temperature, was then done at different working strains $\left(\eta=\ln A_{0} / A\right.$, where $\eta$ is the working strain, $A_{0}$ is the section area of the annealed sample, and $A$ is the section area of the worked sample).

\section{Tensile Testing and Microscopy}

Tensile testing was conducted in a motor-driven testing machine at $293 \mathrm{~K}$ (in air) and at $77 \mathrm{~K}$ (emersed in liquid nitrogen) under displacement control. The displacement rate for each specimen was chosen to correspond to an engineering strain of about $4 \times 10^{-4} / \mathrm{s}$ within the plastic regime. Specimen elongation was monitored by a clip gage inserted between knife edges onto the tensile specimen at the top and bottom of the gage length $(20 \mathrm{~mm})$. Engineering stress and strain data were converted to true stress and true strain by assuming volume conservation during uniform elongation. Taking the derivative of the true-stress $(\sigma) v s$ true-strain $(\varepsilon)$ curve, we calculated the strain-hardening rate $(\theta)$.

Optical microscopy, scanning electron microscopy 
(a) $293 \mathrm{~K}$

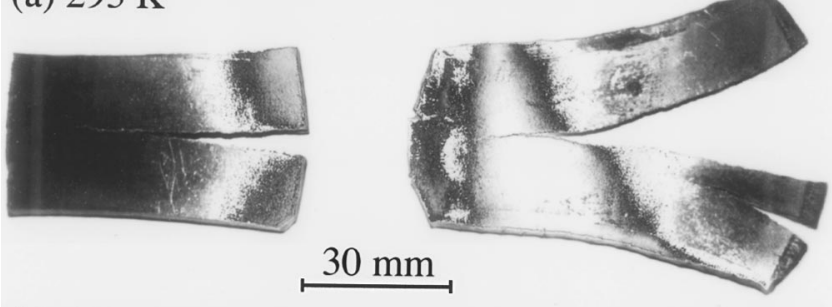

(b) $493 \mathrm{~K}$ heating

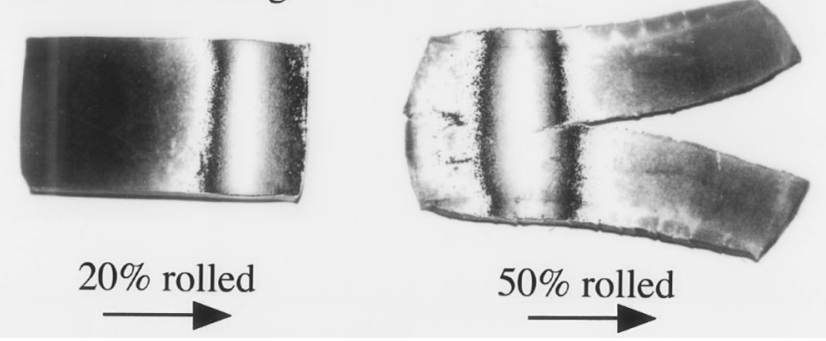

Fig. 3-Test pieces after one-pass rolling at (a) $293 \mathrm{~K}$ and (b) $493 \mathrm{~K}$ for AC material.

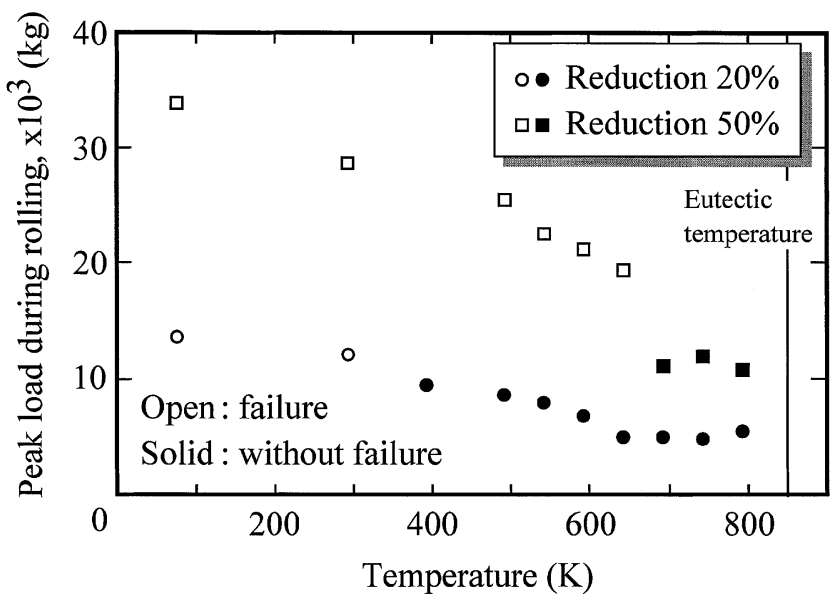

Fig. 4-Deformation resistance of AC material against one-pass rolling with 20 and 50 pct reduction at various temperatures.

(SEM), transmission electron microscopy (TEM), and X-ray analysis were conducted. The TEM samples were prepared parallel to the rolling plane. Samples were finally electropolished at $20 \mathrm{~V}$ in a double-jet polisher at $243 \mathrm{~K}$, using a mixture of 20 pct nitric acid and 80 pct ethanol.

\section{RESULTS AND DISCUSSION}

\section{A. Cast Material Workability}

Figure 3 shows samples after rolling at room temperature. One-pass rolling with either 20 or 50 pct reductions split the sample in two (Figure 3(a)). At higher temperatures, rolling was conducted without sample failure. The temperature limit for working without failure was different for the reductions of 20 and 50 pct (Figure 3(b)). Figure 4 summarizes the results of one-pass rolling. Samples failure occurred below $643 \mathrm{~K}$ for the $50 \mathrm{pct}$ reduction and at $293 \mathrm{~K}$ for the 20 pct reduction. The peak load during rolling decreased

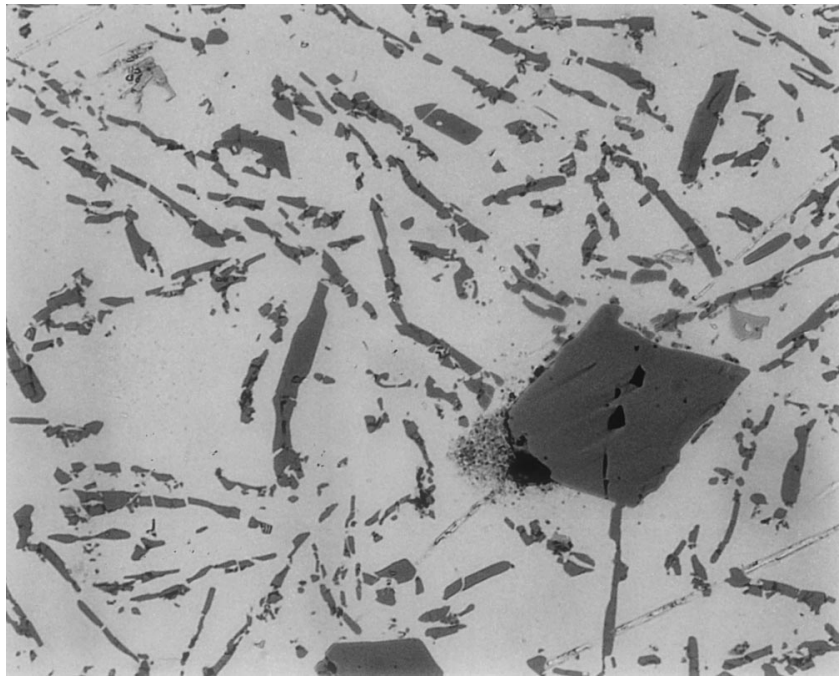

(a)

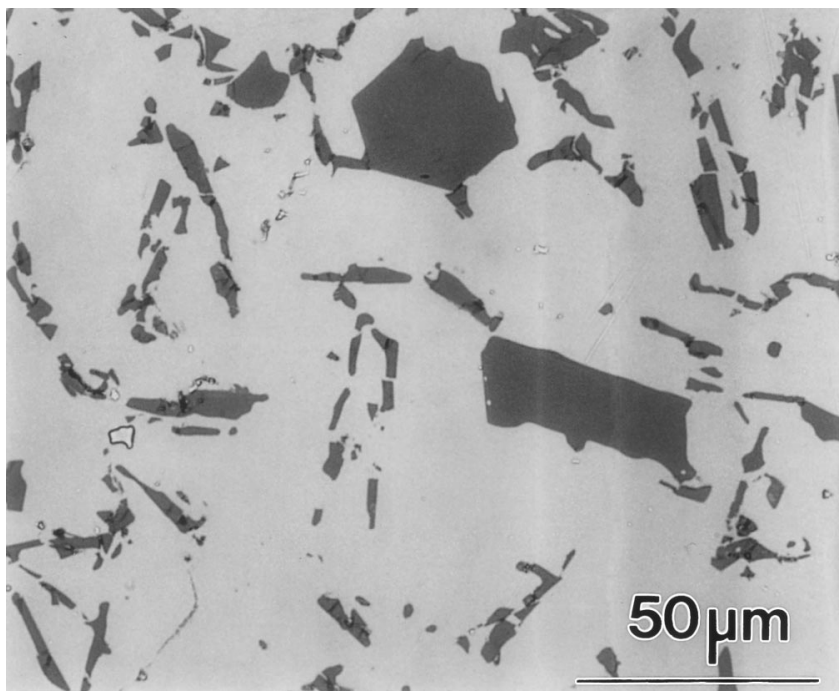

(b)

Fig. 5-Microstructures of specimens after hot rolling: (a) $693 \mathrm{~K}$ with 20 pet reduction and $(b) 793 \mathrm{~K}$ with $50 \mathrm{pct}$ reduction.

continuously with increasing temperature. The peak load of the failed samples was over $12 \times 10^{3} \mathrm{~kg}$ and was higher than that of the wrought ones in both the 20 and 50 pct reductions.

Hot working, generally, refers to deformation under conditions of temperature and strain rate such that recovery processes occur substantially during the deformation process, enabling large strains to be achieved with essentially no strain hardening. It results in decreasing the energy required to deform metal and increasing the flow without cracking. For samples wrought by a 20 pct reduction, cracked primary silicon crystals were scarcely detected above $543 \mathrm{~K}$ (Figure 5(a)). Although primary silicon crystals cracked when worked 50 pct at $593 \mathrm{~K}$, almost no cracks were detected for samples deformed above $793 \mathrm{~K}$ (Figure 5(b)). Severe cracking in silicon crystals occurred in 20 pct cold rolling below $293 \mathrm{~K}$ (Figure 6). Cracks may lead to sample fracture, but may also be useful in refining silicon crystals.

Cold working at room temperature is, thus, suitable for refining the silicon phase, because sample cooling below 


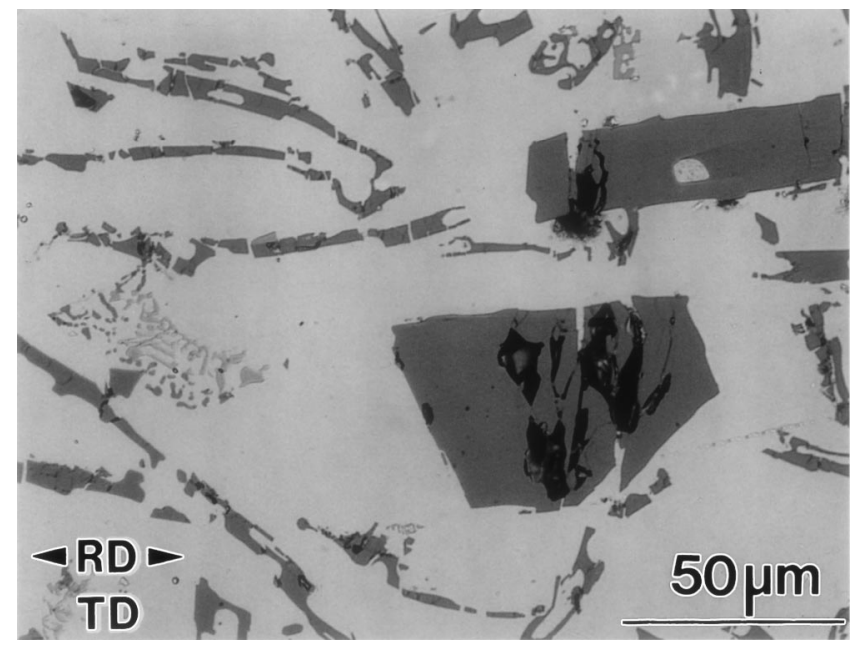

Fig. 6-Microstructure of sample after cold rolling with 20 pct reduction represents cracking in primary silicon phases.

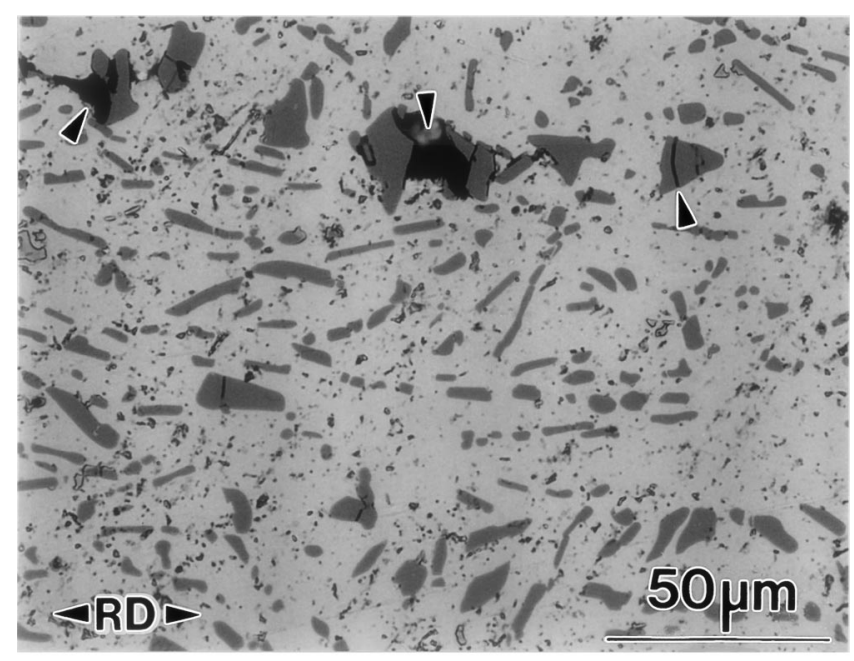

$$
\begin{aligned}
& \text { AC material } \\
& \rightarrow \text { grooved-rolling } \rightarrow \text { annealing : First cycle } \\
& \rightarrow \text { grooved-rolling }
\end{aligned}
$$

Fig. 7-Microstructures of a sample worked by multiple-pass grooved rolling in the second cycle. Arrows indicate cracks in primary silicon crystals.

room temperature is more complicated and costly. To avoid fracture, however, cold working must be done in steps with intermediate annealing. The cold-working limit of the AC material at $293 \mathrm{~K}$ was an approximate 45 pct reduction in section area by swaging and a 23 pct reduction by multiplepass flat rolling.

\section{B. Silicon Crystal Refinement by RTMT}

In a sample cold worked by grooved rolling in the second cycle of deformation, with the silicon refined by cracking (Figure 7), primary silicon crystals are cracked (arrows). Black areas in cracked primary silicon pieces are caused by a lack of particles during metallographical preparation.

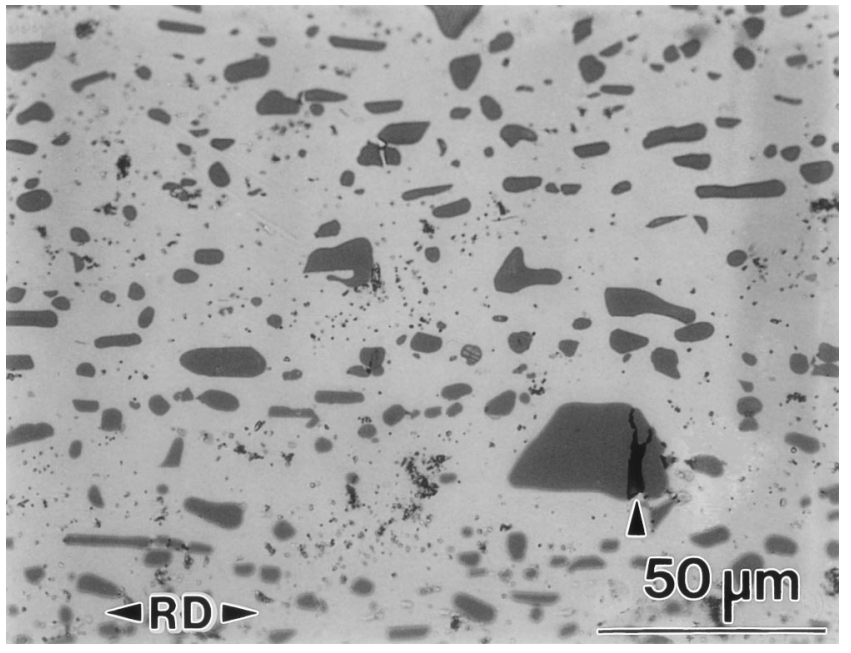

Fig. 8-Microstructure of a sample swaged ( $\eta=0.82)$ for RTMT material. The arrow indicates a crack in the primary silicon crystal.

Cracks in the primary silicon crystal tend to occur normal to the working, or rolling direction (RD) as well as by onepass rolling (Figure 6). Eutectic silicon is also broken and aligned along the RD. Some cracks caused by cold working in the first cycle may heal after annealing and cold working in the second cycle, but cracks introduced in primary silicon crystals remained after successive annealing.

At an approximately 80 pct total reduction, silicon crystals were reduced to a few microns in size and aligned along the RD, although some large silicon crystals remained. Angular fractured silicon particles were spheroidized. Cracks in silicon crystals were hardly detected in the RTMT materials, and cracks in the remaining large silicon crystals of samples worked for RTMT were also limited (Figure 8). Silicon particles in the RTMT materials are about one-fifth of the size of those in the AC material, and their distribution is much more uniform than those in the AC material.

When the second phase ( $\mathrm{Si}$ ) in the soft matrix (Al) is nondeformable, plastic working causes cracking into the second phase. Successive annealing resoftens the coldworked aluminum matrix. Cracks introduced in primary silicon crystals remained even after heat treatment. Subsequent net-compressive working, i.e., rolling or swaging, is believed to make aluminum flow into cracks, so repeating cold working and annealing should eliminate cracks. Spheroidization of silicon crystals by RTMT was attained within several hours, although over 10 hours was needed to spheroidize silicon crystals for conventional Al-Si cast alloys. Thus, RTMT is effective for both cracking silicon crystals and for healing cracks and spheroidizing silicon.

\section{Tensile Properties and Plasticity}

Figure 1(b) shows engineering stress-engineering strain curves for the AC material. The tensile properties of the AC, ST, and RTMT materials are summarized in Table II. Figure 9 shows stress-strain curves of RTMT materials under different conditions. The RTMT material has good strength and ductility; its total elongation exceeds 23 pct at 293 and $77 \mathrm{~K}$ and is much higher than that of the AC and ST materials, and its reduction of area also exceeds 30 pct at both 
Table II. Tensile Properties of Test Materials at 293 and $77 \mathrm{~K}$

\begin{tabular}{|c|c|c|c|c|}
\hline Material & $\begin{array}{c}\text { Temperature } \\
(\mathrm{K})\end{array}$ & $\begin{array}{c}\text { Ultimate } \\
\text { Tensile } \\
\text { Strength } \\
\sigma_{B} \\
(\mathrm{MPa}) \\
\end{array}$ & $\begin{array}{c}\text { Total } \\
\text { Elongation } \\
\text { El (Pct) }\end{array}$ & $\begin{array}{c}\text { Reduction } \\
\text { of Area } \\
\text { RA (Pct) }\end{array}$ \\
\hline \multirow[t]{2}{*}{$\mathrm{AC}$} & 293 & 127 & 7.3 & 15.1 \\
\hline & 77 & 157 & 3.0 & 4.7 \\
\hline \multirow[t]{2}{*}{ ST } & 293 & 142 & 4.7 & 11.1 \\
\hline & 77 & 168 & 2.6 & 5.2 \\
\hline RTMT & 293 & 154 & 23.7 & 30.9 \\
\hline$(\eta=0)$ & 77 & 242 & 25.3 & 30.2 \\
\hline
\end{tabular}

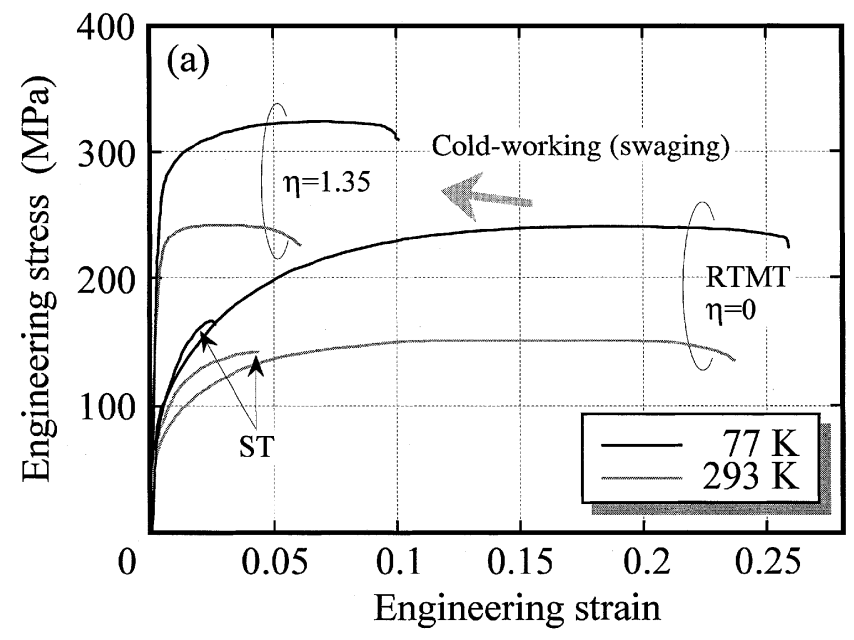

(a)

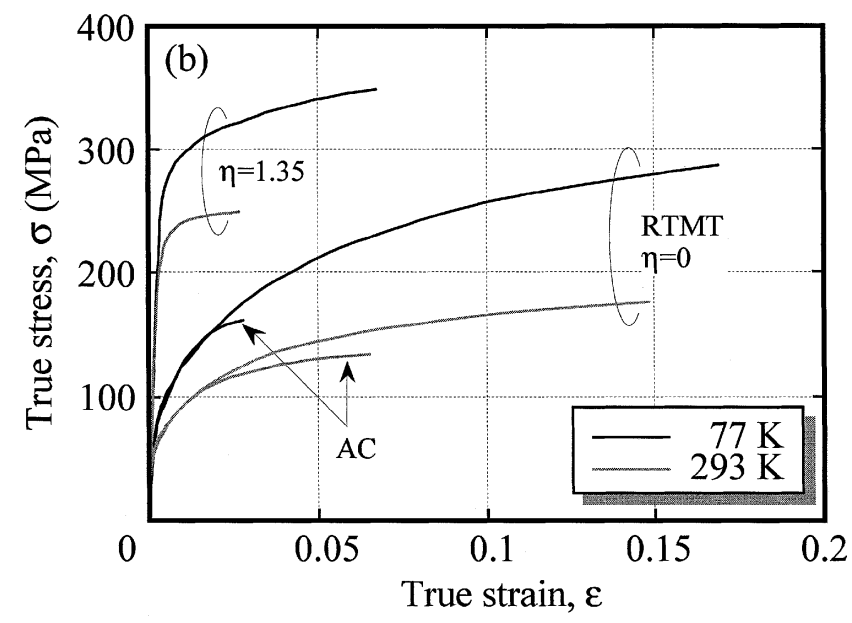

(b)

Fig. 9-Engineering stress $v s$ engineering strain curves $(a)$ of RTMT samples and ST material at 293 and $77 \mathrm{~K}$. (b) True stress $v s$ true strain curves of data in (a) and Fig. 1(b).

testing temperatures. The RTMT material exhibits about a 9 pct local elongation at $293 \mathrm{~K}$, although that of the AC and ST materials is almost zero. It is not only the local elongation, but also the uniform elongation, that is markedly

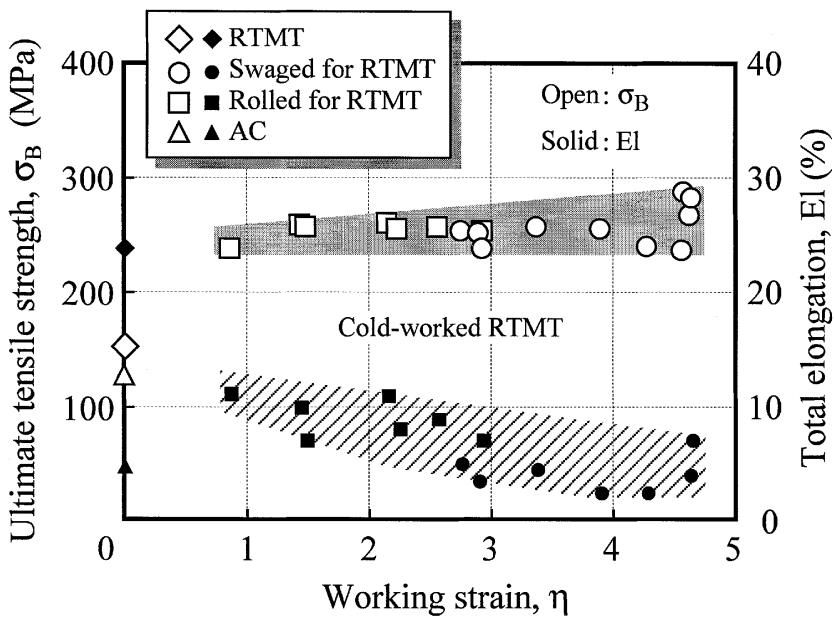

Fig. 10-Relationship of ultimate tensile strength, $\sigma_{B}$, and total elongation, $\mathrm{El}$, of AC and RTMT samples.

increased by RTMT. The increased flow stress with decreasing temperature results in a greater strain to failure for RTMT materials as well as for aluminum (Figure 1(a)), although it results in a lower strain to failure for the AC and ST materials. Thus, refining of nondeformed particles may show the essential ductility of the aluminum matrix.

Cold working increases flow stress and decreases elongation, as in pure aluminum (Figure 1(a)), but the cold-worked samples retained reasonable ductility, i.e., both possessed uniform and local elongations of several percentage points and experienced about a 15 pct reduction of area.

In the relationship between tensile properties and working strain for cold-worked RTMT materials (Figure 10), both sheet and wire materials have excellent plasticity, such as over a 99 pct reduction in section area. The ultimate tensile strength of materials worked by over 56 pct in reduction ranges from 250 to $290 \mathrm{MPa}$ and is twice as high as that of the AC material. Even under heavy cold working, the RTMT samples show good ductility when total elongation exceeds 3 pct.

\section{Strain Hardening}

Figure 11 arranges the data of Figure 9(b) to show the strain-hardening rate. The strain-hardening rate of the RTMT material exceeds that of the AC material, especially at 77 K. Solid-solution hardening may affect strain hardening at initial strains.

An increase in strain hardening generally increases the strain to failure. The RTMT materials exhibit such behavior with decreasing test temperatures (Figure 9(b)). For twophase aluminum alloys, a deformation zone with a high dislocation density and large lattice misorientations was seen near nondeformable large particles, ${ }^{[6]}$ indicating that geometrically necessary dislocations are stored in the deformation zone to accommodate deformation gradients and that they enhance strain hardening, particularly in a low-strain regime. ${ }^{[7]}$ Fine dispersed silicon particles in the RTMT material may also enhance strain hardening with decreasing test temperatures.

Geometrical instability occurs in tensile tests when the 


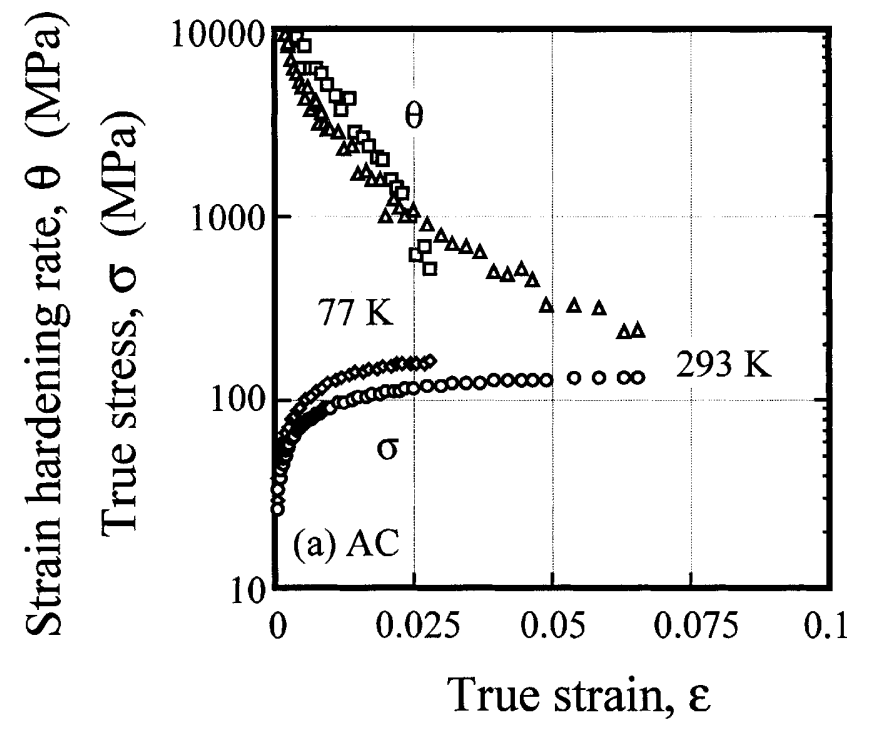

(a)

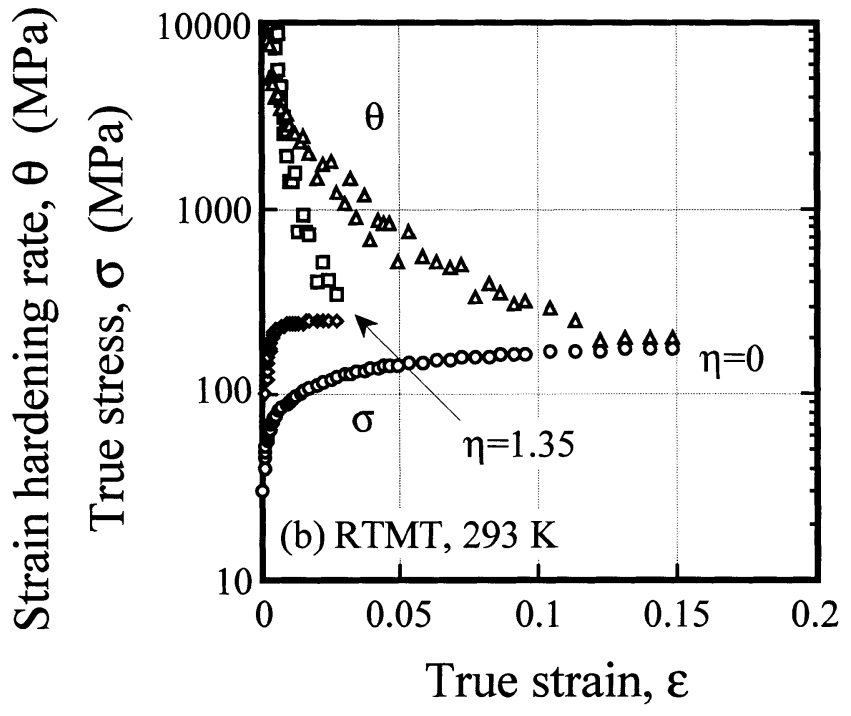

(b)

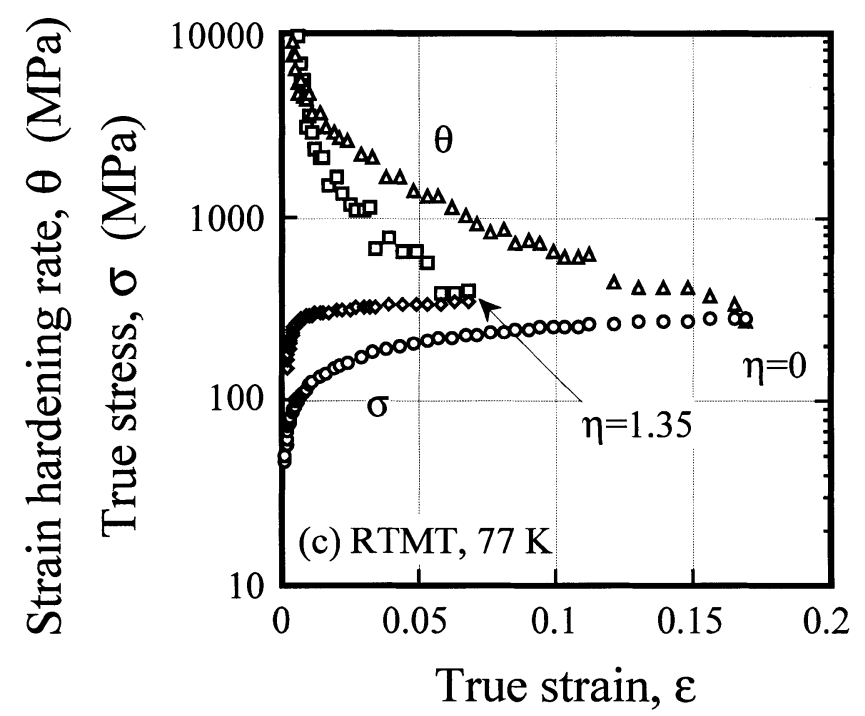

(c)

Fig. 11-Strain-hardening rate and true stress vs true strain from data in Fig. 9(b): (a) AC, (b) RTMT samples at 293 K, and (c) RTMT samples at 77 K.

strain-hardening rate equals the true stress. ${ }^{[10]}$ Cold working increases the strain-hardening rate at initial strains, but this rapidly decreases as the strain increases (Figures 11(b) and (c)). The RTMT samples under both annealed and coldworked conditions show necking instability, but the AC material fractures before reaching this, especially at $77 \mathrm{~K}$ (Figure 11(a)). Thus, refining of silicon crystals primarily results in the avoidance of early fracture and shows the essential ductility of the aluminum matrix.

Reinforcing aluminum alloys with $\mathrm{SiC}$ particles strengthened the alloys at low strains, due to increases in elastic modulus and strain-hardening rate. ${ }^{[4,5]}$ The RTMT materials also contain silicon particles about the same size as the $\mathrm{SiC}$ particles in reinforced aluminum alloys. In microstructure and performance, the RTMT material is properly called a metal-matrix composite: the matrix and reinforcement were chemically distinct, with a definite interface, were combined three-dimensionally, and possessed properties not obtained from the two individual constituents. ${ }^{[11]}$

\section{E. Microstructure of Heavily Cold-Worked Materials}

In a rolled RTMT sample with $\eta=3$ (Figure 12), silicon particles are aligned parallel to the RD. In X-ray pole figures of a rolled RTMT sample with $\eta=3.2$ (Figure 13), the matrix exhibited a texture similar to wrought aluminum. ${ }^{[12]}$ The silicon phase also showed a preferred orientation (Figure 13(b)). Many voids were observed in the heavily coldworked RTMT material (Figure 12), and such voids mostly formed in the aluminum matrix, but not in the interface region between silicon particles and the matrix.

The matrix of heavily cold-worked RTMT materials had subgrains about $200 \mathrm{~nm}$ in diameter, as a consequence of dynamic recovery (Figure 14). A high dislocation density 

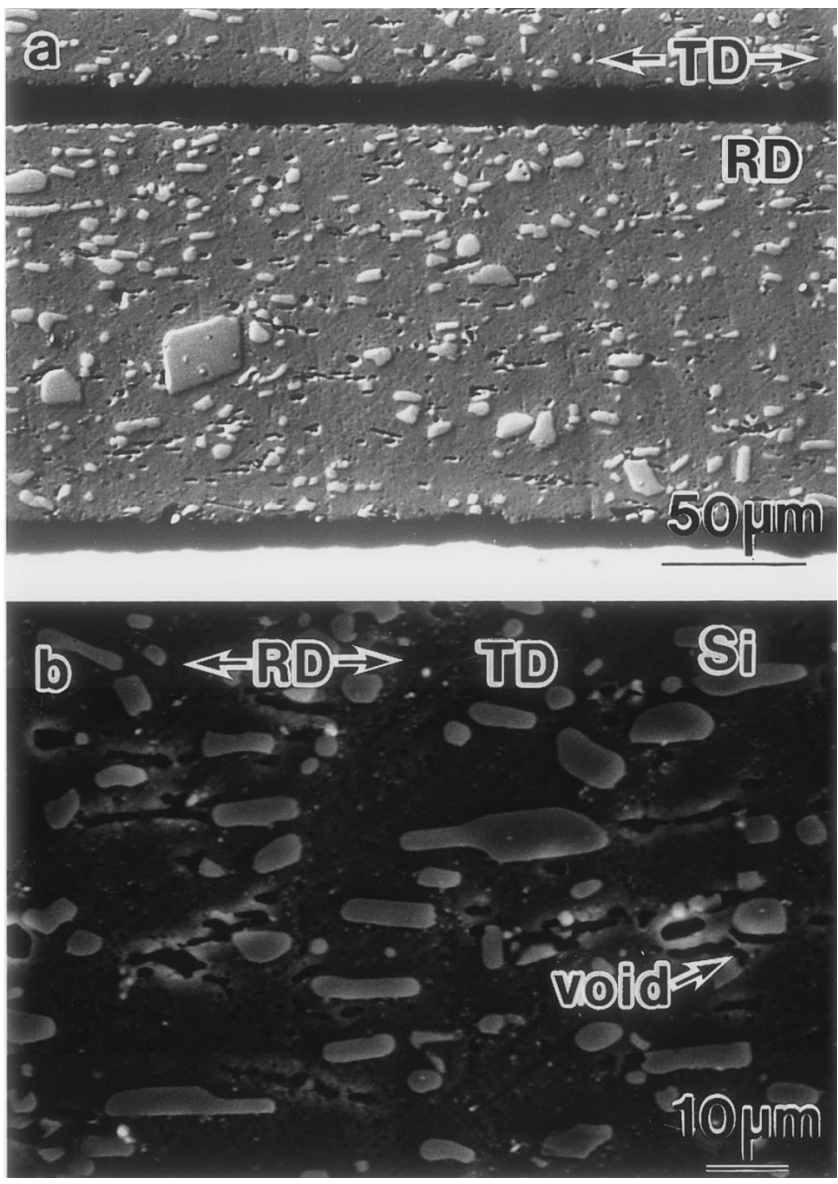

Fig. 12-SEM micrographs of sample rolled $(\eta=3.0)$ for RTMT material: (a) BSI for the RD section and (b) SEI for the TD section.

accumulated at nondeformable particles in a deformed matrix, and small equiaxed subgrains were observed near nondeformable large particles. ${ }^{[6]}$ The RTMT fragmented silicon crystals, then caused the silicon particles to be distributed uniformly. Such a fine dispersion of nondeformable particles should provide a subgrain structure under heavy cold working.

\section{F. Tensile-Property Balance}

Figure 15 replots Figure 10 data, showing the relationship between ultimate tensile strength and total elongation with wrought alloys. ${ }^{[13]}$ An adequate balance of these properties is obtained within the range of the trend band. If the finished product must be stronger than the fully annealed material, the final operation must be a cold-working step with the proper degree of deformation to produce the desired strength. Such a procedure for developing a certain combination of strength and ductility in the final product is more successful than trying to achieve the same combinations of properties by partially softening a fully cold-worked material, because recrystallization proceeds relatively rapidly. ${ }^{[14]}$ In this study, a eutectic binary Al-Si system was used as a model alloy and did not contain strengthening alloy elements such as magnesium and copper. It is, thus, possible to improve the properties of RTMT materials by combining them with solidsolution hardening and/or precipitation hardening.

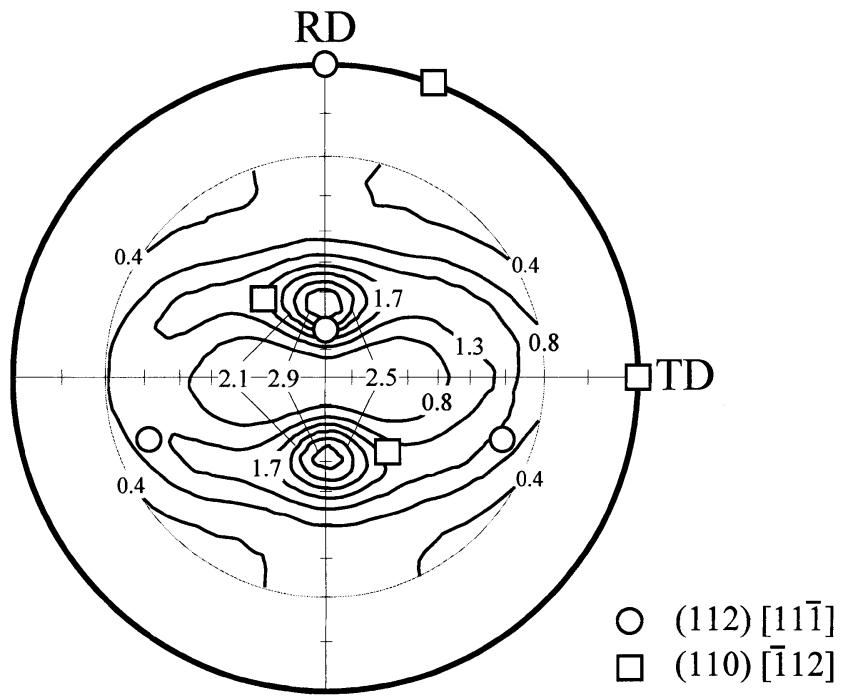

(a)

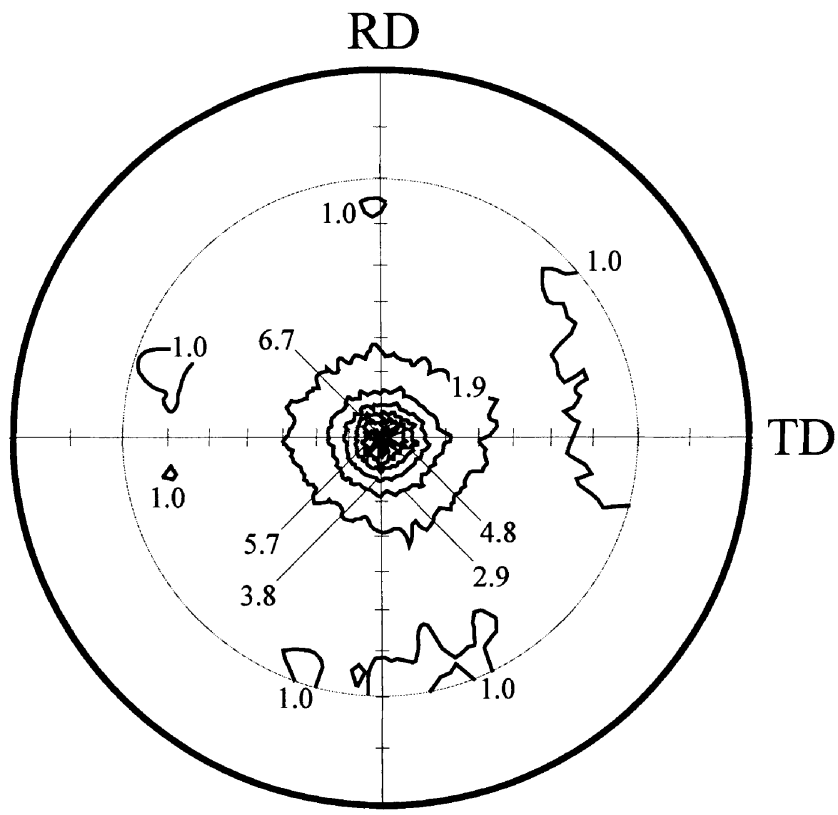

(b)

Fig. 13-X-ray pole figure of a sample rolled $(\eta=3.2)$ for RTMT material: (a) $\mathrm{Al}\{111\}$ and $(b) \mathrm{Si}\{111\}$.

\section{CONCLUSIONS}

We applied a novel RTMT to an Al-12.6 wt pet Si cast alloy. The process produced microstructural refining and improved tensile properties. It also made $\mathrm{Al}-\mathrm{Si}$ cast alloys a good model for recyclable material design. The major results are summarized as follows.

1. Although severe cracking occurred in silicon crystals during cold working the stepwise deformation led to the development of a refined microstructure. Then, the RTMT, which was carried out in several steps with intermediate annealing operations, was developed. This process could develop a refined microstructure, where both eutectic and primary silicon phases were broken into some fragments and finely dispersed in the aluminum 

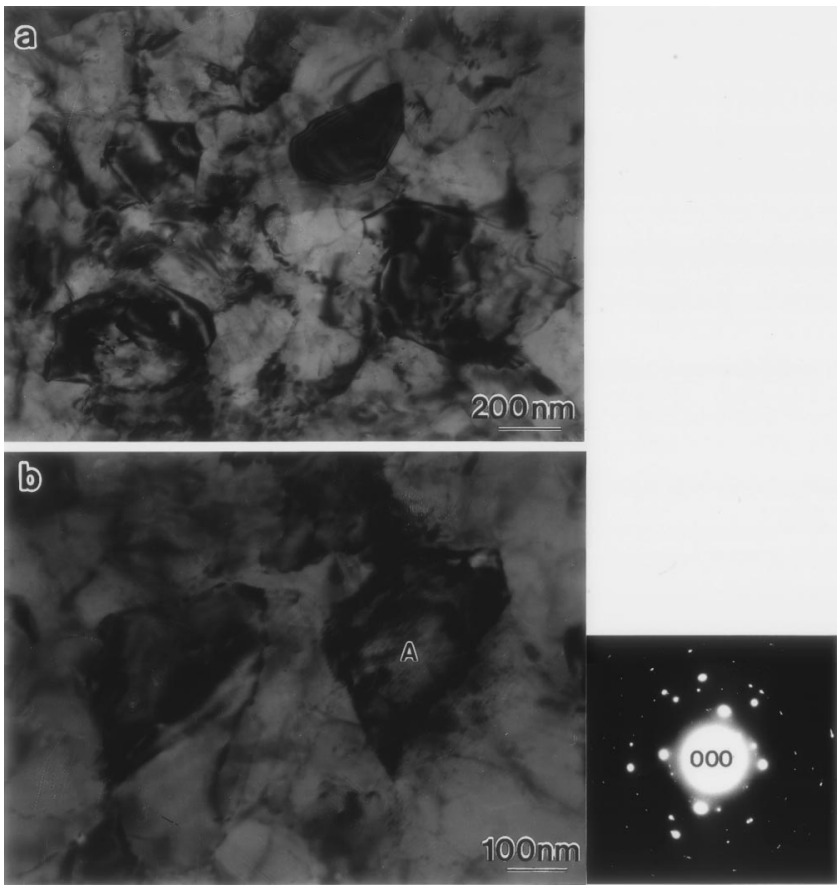

Fig. 14-(a) and (b) TEM micrographs of a sample rolled $(\eta=3.0)$ for RTMT material. Beam direction is parallel to [011] in grain A.

matrix. The cracks in the silicon were filled by an aluminum matrix during RTMT, and the angular fractured silicon particles were spherodized. Most of the silicon crystals in the RTMT material were about a few micrometers in size and were much smaller than those in the cast material.

2. At room temperature, the RTMT materials had a significantly enhanced ductility, such as a 24 pct total elongation in tensile tests, and showed a heavy plasticity, such as up to strain five (99 pct reduction).

3. The cold-worked RTMT materials exhibited a good balance between tensile strength and elongation and also showed a higher strain-hardening rate in the low-strain regime than the cast material. The tensile strength of cold-worked materials ranged from 250 to $290 \mathrm{MPa}-$ about twice that of the cast material.

4. For heavily cold-worked materials, the Al matrix showed the texture typical of wrought materials and a subgrain structure about $200 \mathrm{~nm}$ in diameter.

\section{ACKNOWLEDGMENTS}

The authors acknowledge the suggestions of an anonymous reviewer.

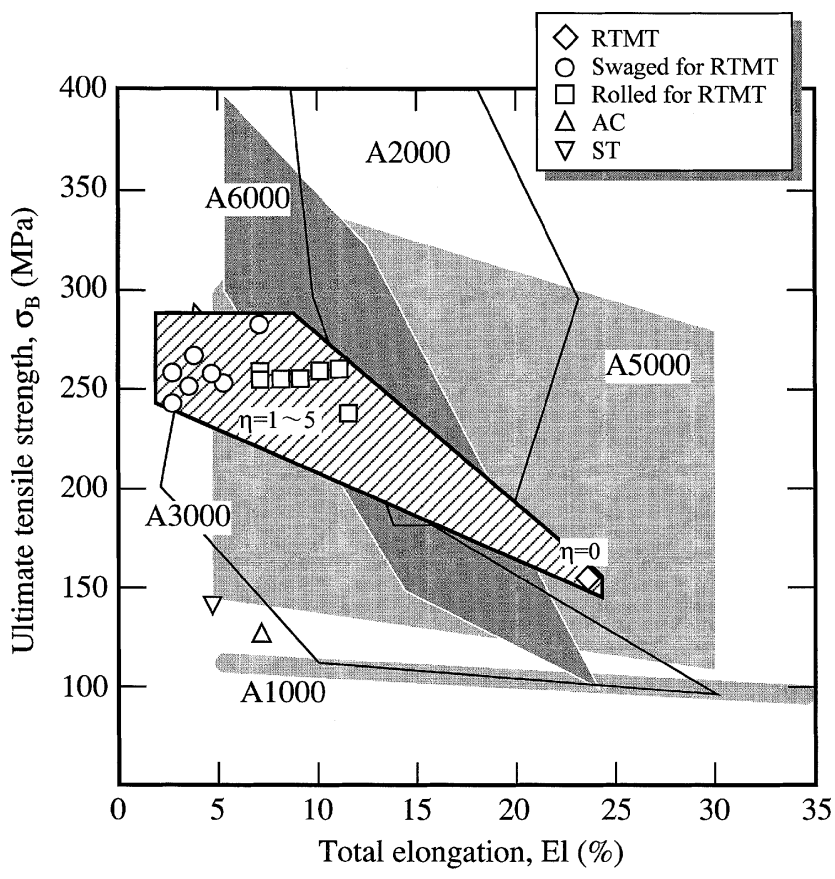

Fig. 15-Strength-elongation balance map for test materials and wrought alloy. ${ }^{[13]}$ Plots are from data in Fig. 10.

\section{REFERENCES}

1. K. Nagai: Trans. Mater. Res. Soc. Jpn., 1994, vol. 18A, pp. 139-42.

2. Introduction to Recyclable Design for Sustainable Development, K. Nagai, ed., Kagaku-Kogyo-Nippou, Tokyo, 1995 (in Japanese).

3. O. Umezawa and K. Nagai: Trans. Mater. Res. Soc. Jpn., 1996, vol. 20, pp. 190-93.

4. J.M. Papazian and P.N. Adler: Metall. Trans. A, 1990, vol. 21A, pp. 401-10.

5. S.F. Corbin and D.S. Wilkinson: Acta Metall. Mater, 1994, vol. 42, pp. 1319-27.

6. F.J. Humphreys: Acta Metall., 1977, vol. 25, pp. 1323-44.

7. M.F. Ashby: Phil. Mag., 1970, vol. 21, pp. 399-424.

8. P.J. Ward, H.V. Atkinson, P.R.G. Anderson, L.G. Elias, B. Garcia, L. Kahlen, and J-M. Rodriguez-Ibabe: Acta Metall. Mater, 1996, vol 44, pp. 1717-27.

9. K. Nagai and O. Umezawa: Japan Patent Claim Open No. H10-1757, 1998 (in Japanese).

10. R.W.K. Honeycombe: The Plastic Deformation of Metals, 2nd ed. Edward Arnold, London, 1984, p. 457.

11. M. Taya and R.J. Arsenault: Metal Matrix CompositesThermomechanical Behavior, Pergamon Press, Oxford, United Kingdom, 1989.

12. H. Hu, P.R. Sperry, and P.A. Beck: Trans. AIME - JOM, 1952, vol 194, pp. 76-81.

13. Microstructure and Property of Aluminum, Japan Institute of Light Metals, Tokyo, 1991 (in Japanese).

14. G. Dieter: Mechanical Metallurgy, 3rd ed, McGraw-Hill, New York, NY, 1986, p. 529. 